\title{
Kinetic modeling of secondary organic aerosol formation: effects of particle- and gas-phase reactions of semivolatile products
}

\author{
A. W. H. Chan ${ }^{1}$, J. H. Kroll ${ }^{1,2}$, N. L. $\mathbf{N g}^{1}$, and J. H. Seinfeld ${ }^{1}$ \\ ${ }^{1}$ Departments of Environmental Science and Engineering and Chemical Engineering, California Institute of Technology, \\ Pasadena, CA 91125, USA \\ ${ }^{2}$ now at: Aerodyne Research Inc., Billerica, MA 01821, USA
}

Received: 7 May 2007 - Published in Atmos. Chem. Phys. Discuss.: 24 May 2007

Revised: 1 August 2007 - Accepted: 3 August 2007 - Published: 7 August 2007

\begin{abstract}
The distinguishing mechanism of formation of secondary organic aerosol (SOA) is the partitioning of semivolatile hydrocarbon oxidation products between the gas and aerosol phases. While SOA formation is typically described in terms of partitioning only, the rate of formation and ultimate yield of SOA can also depend on the kinetics of both gas- and aerosol-phase processes. We present a general equilibrium/kinetic model of SOA formation that provides a framework for evaluating the extent to which the controlling mechanisms of SOA formation can be inferred from laboratory chamber data. With this model we examine the effect on SOA formation of gas-phase oxidation of first-generation products to either more or less volatile species, of particlephase reaction (both first- and second-order kinetics), of the rate of parent hydrocarbon oxidation, and of the extent of reaction of the parent hydrocarbon. The effect of pre-existing organic aerosol mass on SOA yield, an issue of direct relevance to the translation of laboratory data to atmospheric applications, is examined. The importance of direct chemical measurements of gas- and particle-phase species is underscored in identifying SOA formation mechanisms.
\end{abstract}

\section{Introduction}

Particulate matter formed by condensation of oxidation products of volatile organic compounds (VOCs), termed secondary organic aerosol (SOA), can contribute a significant fraction of airborne particulate matter (Seinfeld and Pandis, 2006). Environmental chamber studies are the principal means by which the aerosol-forming potential of VOCs is established. SOA formation is a complex process, involving gas-phase oxidation chemistry, partitioning of oxidation products between the gas and particle phases, and aerosol-

Correspondence to: J. H. Seinfeld

(seinfeld@caltech.edu) phase chemistry. While it is possible, in principle, to simulate SOA formation using explicit, detailed gas-phase chemical mechanisms coupled to gas-particle equilibrium (Johnson et al., 2006; Griffin et al., 2002a, b; Pun et al., 2002), those mechanisms currently used in regional and global atmospheric chemical transport models are generally semiempirical, the parameters of which are derived from laboratory chamber studies. The cornerstone of SOA formation is the generation of semivolatile oxidation products that undergo absorptive partitioning between the gas and particulate phases (Seinfeld and Pankow, 2003; Pankow, 1994a, b; Donahue et al., 2006). A consequence of the absorptive partitioning is that SOA formation depends not only on the amount and volatility of these oxidation products, but also on the amount and nature of the aerosol mass into which the compounds partition.

A widely-used semi-empirical mechanism for SOA formation is the Odum model (Odum et al., 1996, 1997), in which oxidation of the parent VOC leads to semivolatile firstgeneration products, and in which the SOA yield, $Y$, of a particular VOC, defined as the ratio of mass of SOA formed, $\Delta M_{o}$, to the mass of hydrocarbon reacted, $\triangle H C$, is given by

$Y=\frac{\Delta M_{o}}{\Delta H C}=M_{o} \sum_{i=1}^{n} \frac{\alpha_{i} K_{p, i}}{1+K_{p, i} M_{o}}$

where $\alpha_{i}$ is the mass-based stoichiometric coefficient of semivolatile product $i, K_{p, i}$ is its gas-particle partitioning equilibrium constant, and $M_{o}$ is the total mass concentration of the absorbing (aerosol) medium. Equation (1) has traditionally been used to describe the yield of SOA as a function of total organic aerosol loading, $M_{o}$, after the parent hydrocarbon has been entirely consumed. In a typical experimental study, a set of data of $Y$ versus $M_{o}$, the characteristic "yield curve" for a particular VOC, is fitted to Eq. (1), by varying $\alpha_{i}$ and $K_{p, i}$ (typically $n=2$ ), in which each product has a different volatility (see "Odum Model" in Fig. 1), is sufficient in describing the experimental SOA yield for most VOCs.

Published by Copernicus Publications on behalf of the European Geosciences Union. 


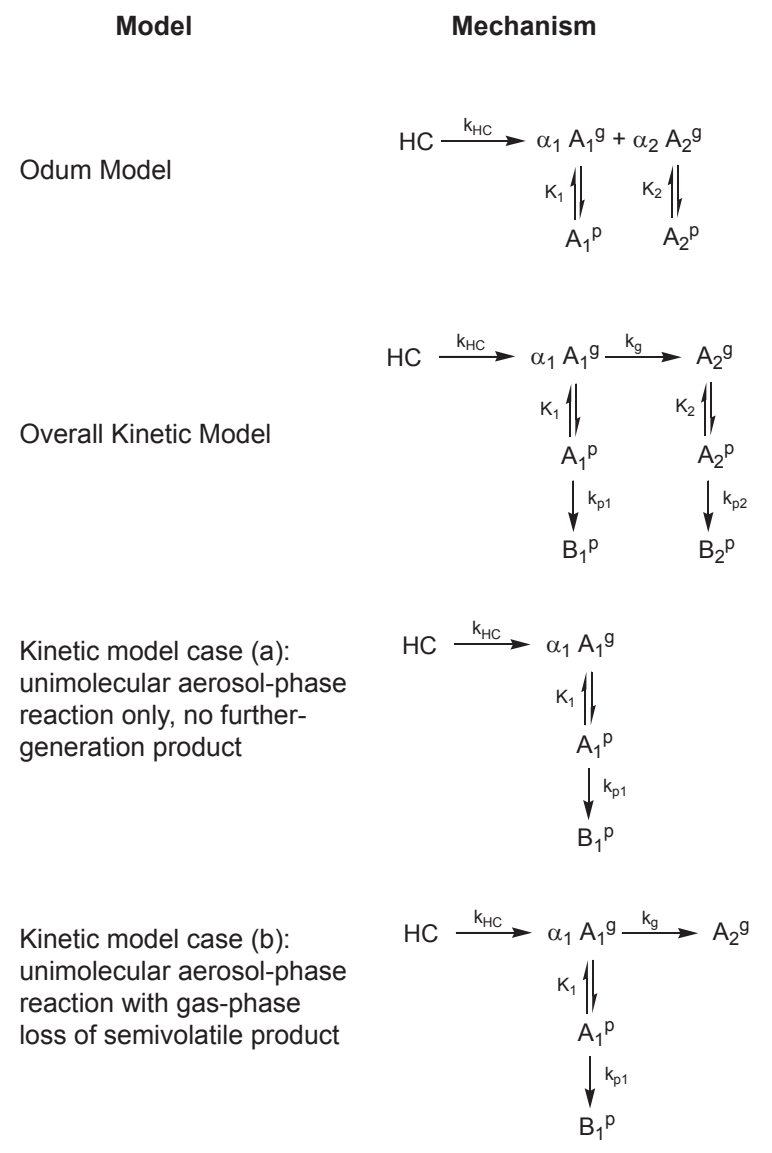

Fig. 1. Kinetic schemes for SOA formation.

It is important to note that the model underlying Eq. (1) is an equilibrium rather than kinetic model in that it relates the mass of aerosol formed, $\Delta M_{o}$, to $\triangle H C$ without regard to the rate at which the parent hydrocarbon is oxidized. This model has been used to empirically represent SOA yields for more than 50 different parent VOCs (see Seinfeld and Pankow, 2003).

Aerosol-phase reactions involving condensed semivolatile compounds are known to be important in SOA formation, evidence for which includes the presence of high molecular weight oligomers in SOA (Gao et al., 2004a, b; Tolocka et al., 2004; Kalberer et al., 2004) and increased SOA yields under acidic conditions (Gao et al., 2004a, b; Iinuma et al., 2004; Jang et al., 2002; Czoschke et al., 2003). Kroll and Seinfeld (2005) showed that if a semivolatile product undergoes a reversible, unimolecular reaction with an equilibrium constant, $K_{r x n}$, in the aerosol phase, the corresponding gas-particle partitioning equilibrium constant $K_{p}$ in the Odum model can be replaced by a total gas-particle partitioning equilibrium constant $\left(K^{*}\right)$, which includes contribution from particle-phase processes. The thermal stability of some aerosol-phase reaction products, such as peroxyhemiacetals (Tobias and Ziemann, 2000), esters (Surratt et
Kinetic model case (c): further gas-phase oxidation to form semivolatile product

Kinetic model case (d): further gas-phase oxidation, first-generation volatile product

Kinetic model case (e): bimolecular aerosol-phase reaction only, no furthergeneration product

Kinetic model case (f): bimolecular aerosol-phase reaction with gas-phase loss of semivolatile product

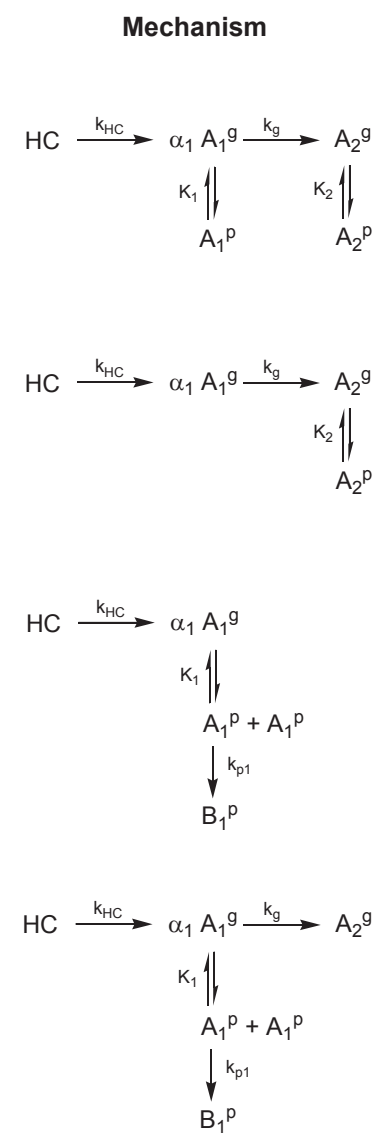


of SOA formation that include both equilibrium and kinetic processes. Given a set of experimental data, the models would allow one to evaluate the extent to which the observed SOA formation data are consistent with particular controlling mechanisms and thereby suggest avenues for more in-depth study.

\section{Model description}

The set of kinetic models is given in Fig. 1. The overall kinetic model is shown, together with special cases, denoted (a)-(f). In each case, the parent hydrocarbon is oxidized to a first-generation product denoted $\mathrm{A}_{1}^{\mathrm{g}}$ (with pseudo-first-order rate constant $k_{H C}$ and mass stoichiometric coefficient $\alpha_{1}$ ). The models are developed considering only one oxidation product; they can readily be extended to a spectrum of oxidation products (Donahue et al., 2006). If there is initial organic material present $\left(M_{o}(0)>0\right)$, and $\mathrm{A}_{1}$ is semivolatile (as it is for all cases except case (d)), $A_{1}^{\mathrm{g}}$ immediately partitions into the particulate phase as $\mathrm{A}_{1}^{\mathrm{p}}$ with a partitioning coefficient $K_{1}$; otherwise, $\mathrm{A}_{1}^{\mathrm{g}}$ partitions only after it reaches its saturation concentration in the gas phase. Instantaneous partitioning equilibrium can be assumed, since the characteristic timescale for gas-particle transport is typically much faster than that for oxidation of the parent hydrocarbon (Bowman et al., 1997). Aerosol-phase reaction is represented by irreversible conversion of $A_{1}^{\mathrm{p}}$ to $\mathrm{B}_{1}^{\mathrm{p}}$. As noted, Kroll and Seinfeld (2005) have considered the case of reversible aerosol-phase reaction. The aerosol-phase reaction can also be represented as a bimolecular reaction; this is included in cases (e) and (f). The first-generation semivolatile product $\mathrm{A}_{1}^{\mathrm{g}}$ can be further oxidized in the gas phase, represented by first-order reaction of $\mathrm{A}_{1}^{\mathrm{g}}$ with a rate constant $k_{g}$ to form a second-generation semivolatile product or a volatile product, $A_{2}^{\mathrm{g}}$. $A_{2}^{\mathrm{g}}$ itself may then partition as $A_{2}^{p}$, which itself may also react irreversibly in the aerosol phase to form $\mathrm{B}_{2}^{\mathrm{p}}$.

The qualitative kinetic behavior of the general system depends on the magnitudes of the various rate constants relative to the intrinsic $\mathrm{HC}$ oxidation rate constant $k_{H C}$, as reflected by the ratios, $\beta_{g}\left(=k_{g} / k_{H C}\right), \beta_{p 1}\left(=k_{p 1} / k_{H C}\right)$, and $\beta_{p 2}$ $\left(=k_{p 2} / k_{H C}\right)$. In general, the quantities, $k_{H C}$ and $M_{o}(0)$, are known. The most general form of the kinetic model admits a number of special cases, (a)-(f) depending on the relative values of the parameters.

\section{General model behavior}

The purpose of this section is to examine the qualitative nature of SOA formation as would be observed experimentally if the mechanism of SOA formation adheres to each of the cases in Fig. 1. This will allow us to assess the sensitivity of the dynamic SOA formation processes to the particular mechanism involved.

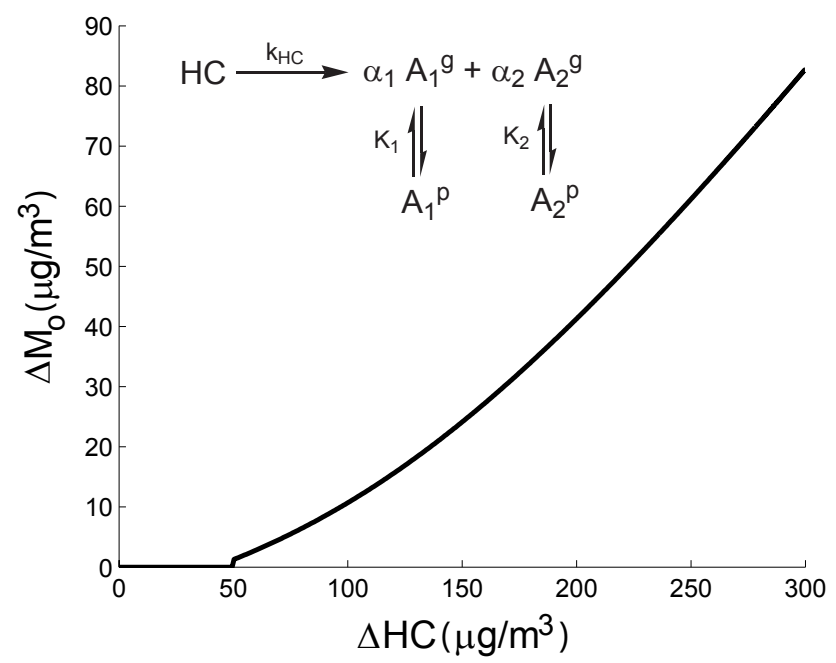

Fig. 2. Characteristic growth curve ( $\triangle M_{O}$ vs $\triangle H C$ ) for the twoproduct Odum model (Eq. 1). $\left(H C(0)=300 \mu \mathrm{g} / \mathrm{m}^{3}, M_{o}(0)=0\right.$, $\left.\alpha_{1}=0.4, K_{1}=0.01 \mathrm{~m}^{3} / \mu \mathrm{g}, \alpha_{2}=0.1, K_{2}=0.2 \mathrm{~m}^{3} / \mu \mathrm{g}\right)$ The discontinuity at $H C(0)=50 \mu \mathrm{g} / \mathrm{m}^{3}$ is a result of the instantaneous equilibria of two semivolatile products with different partitioning coefficients. When the less volatile product (product 2) saturates and begins to form aerosol, it provides an absorbing medium for the more volatile product (product 1) to condense instantaneously.

\subsection{Odum model}

Figure 2 shows the characteristic time-dependent growth curve of SOA $\left(\Delta M_{o}\right)$ versus HC reacted $(\triangle H C)$ for the Odum model (assuming two semivolatile products). At low $\triangle H C$ and $M_{o}(0)=0$, no aerosol forms until the condensable products exceed their saturation concentrations. Because this is strictly an equilibrium model, aerosol growth follows the same curve regardless of the initial HC concentration $(H C(0))$. Aerosol formation is governed only by the timescale of $\mathrm{HC}$ oxidation.

3.2 Case (a): First-generation product only with aerosolphase reaction

Case (a) in Fig. 1 includes irreversible reaction of the firstgeneration semivolatile product in the aerosol phase. When particle-phase reaction is slow compared to $\mathrm{HC}$ oxidation ( $\beta_{p 1}=0.1$, see panel (a) of Fig. 3), only after most of the HC has been consumed does $A_{1}^{p}$ react to form an appreciable amount of $\mathrm{B}_{1}^{\mathrm{p}}$, drawing the partitioning equilibrium toward the aerosol phase. This behavior is evidenced by significant growth (the vertical portion) after $\mathrm{HC}$ is essentially consumed. If the aerosol-phase reaction is irreversible, the semivolatile product is entirely converted to $\mathrm{B}_{1}^{\mathrm{p}}$, and the final SOA yield is simply $\Delta M_{o}=\alpha_{1} \Delta H C$. This gives rise to two distinct regions in the growth curve: the first associated with the early gas-particle partitioning and the second associated with the slower aerosol-phase reaction. If the aerosol-phase 
(a)

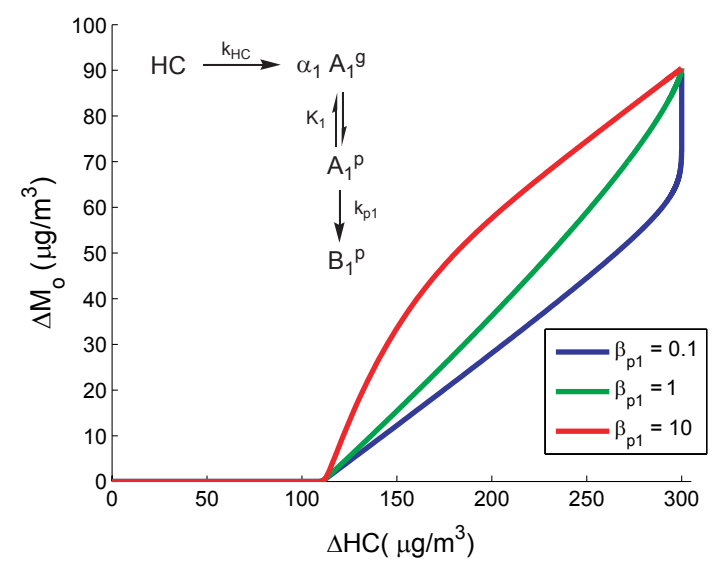

(b)

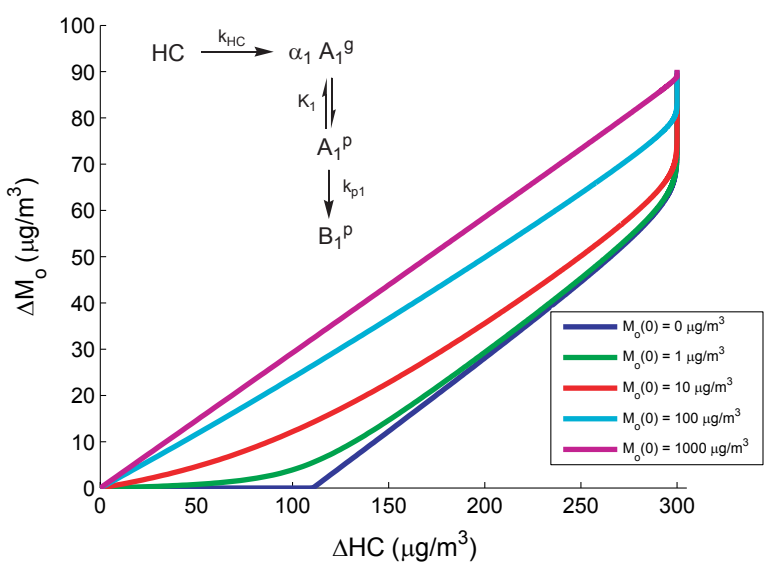

Fig. 3. Characteristic growth curves for formation of firstgeneration product only with aerosol-phase reaction (case (a)), with $\alpha_{1}=0.3$. Panel (a): Growth curves for a fast (red), medium (green), and slow (blue) aerosol phase reaction. Panel (b): Effect of changing initial amount of organic material $M_{o}(0)$ for $\beta_{p 1}=0.1$.

reaction is fast relative to $\mathrm{HC}$ oxidation $\left(\beta_{p 1}=10\right.$, see panel (a) of Fig. 3), as soon as $A_{1}^{p}$ is formed it is quickly converted to $\mathrm{B}_{1}^{\mathrm{p}}$. $\quad \mathrm{A}_{1}^{\mathrm{g}}$ continues to condense to maintain partitioning equilibrium, leading to rapid aerosol formation. $A_{1}^{g}$ is eventually entirely depleted because its rate of loss through $A_{1}^{p}$ exceeds the rate of supply from the $\mathrm{HC}$ oxidation. Again, if the aerosol-phase reaction is irreversible, all of oxidation product $A_{1}$ must eventually be converted to the nonvolatile aerosol-phase reaction product $\mathrm{B}_{1}^{\mathrm{p}}$, regardless of the value of $\beta_{p 1}$. As a result, for this mechanism the final SOA yield is independent of the initial hydrocarbon concentration, and the yield curve $\left(\triangle M_{o} / \triangle H C\right)$ is independent of the organic aerosol mass concentration.

The amount of initial organic material present, $M_{o}(0)$, also affects the shape of the growth curve, as shown in panel (b) of Fig. 3. As $M_{o}(0)$ increases, the partitioning equilibrium

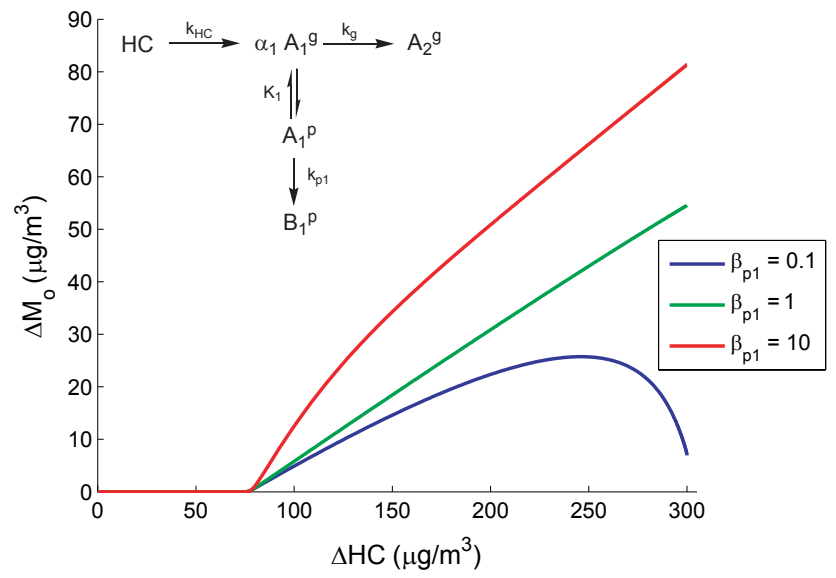

Fig. 4. Characteristic growth curves for formation of firstgeneration product with unimolecular aerosol-phase reaction and with gas-phase conversion to a volatile second-generation product (case (b)). The curves shown here are for fast (red), medium (green) and slow (blue) aerosol-phase reactions and $\beta_{g}=1, \alpha_{1}=0.3$.

is shifted in favor of $A_{1}^{p}$. Initial SOA formation occurs earlier, so that at any particular value of $\triangle H C$, the larger the value of $M_{o}(0)$, the greater the amount of aerosol formed. Once the initial hydrocarbon is consumed, the amount of SOA formed is the same regardless of $M_{o}(0)$, although the paths by which $\Delta M_{o}$ approach the final yield are quite different; this is an important observation relative to comparison of experimentally-determined SOA yields when the initial hydrocarbon is not entirely reacted.

3.3 Case (b): First-generation product with unimolecular aerosol-phase reaction and with gas-phase conversion to a volatile second-generation product

Case (b) has been considered in Kroll et al. (2007). Irreversible loss of gas-phase semivolatile product can occur either by chemical reaction (further oxidation) or physical processes (scavenging, wall loss). Aerosol formation depends on the competition between the formation of $B_{1}^{p}$ and $A_{2}^{g}$. The final yield is governed not only by the partitioning between $A_{1}^{g}$ and $A_{1}^{p}$, but also by the relative rates of gas-phase loss of first-generation product and aerosol-phase reaction. The SOA yield differs for different amounts of initial organic material present, despite the same total organic aerosol loading; consequently, the SOA yield could be underestimated in chamber experiments owing to the induction period associated with the absence of organic or inorganic seed particles (Kroll et al., 2007).

Figure 4 shows growth curves for kinetic model case (b). If the rate of the aerosol-phase reaction substantially exceeds that of the gas-phase loss $\left(\beta_{p 1}=10\right)$, the growth curve is similar to that in case (a), and most $A_{1}^{g}$ condenses and forms $\mathrm{B}_{1}^{\mathrm{p}}$. As $\beta_{p 1}$ decreases, the final yield decreases, as more 
of the oxidation product $\mathrm{A}_{1}$ is ultimately converted to $\mathrm{A}_{2}^{\mathrm{g}}$. At $\beta_{p 1}=0.1$, the aerosol-phase reaction is sufficiently slow that $A_{1}^{\mathrm{p}}$ repartitions to the gas phase and is lost to $A_{2}^{\mathrm{g}}$, and, as a result, total SOA mass reaches a maximum and decreases. Case (b) also provides a possible representation for the "acid catalysis" effect when competing gas-phase reactions are present, in which acidity can increase the overall ("final") SOA yield by catalyzing the rate of the aerosolphase reaction.

Since SOA formation in case (b) depends on both the gas-particle partitioning equilibrium between $\mathrm{A}_{1}^{\mathrm{g}}$ and $\mathrm{A}_{1}^{\mathrm{p}}$ and the relative rates of gas-phase loss and aerosol-phase reaction, the initial amount of organic material affects the relative amounts of $\mathrm{A}_{1}^{\mathrm{p}}$ and $\mathrm{A}_{1}^{\mathrm{g}}$, and thus the relative rates of gas-phase and aerosol-phase reactions. Kroll et al. (2007) showed that less gas-phase semivolatile oxidation product is lost irreversibly with the introduction of seed particles because the induction period for SOA growth is shorter, leading to higher SOA yields, despite constant total organic aerosol loading.

3.4 Case (c): First- and second-generation semivolatile products with no aerosol-phase reaction

Case (c) includes the contribution of semivolatile compounds formed from further gas-phase reaction of the firstgeneration product. If gas-phase conversion of $A_{1}^{g}$ to $A_{2}^{g}$ is relatively slow (e.g. $\beta_{g}=0.1$ ), the second-generation aerosol product $\mathrm{A}_{2}^{\mathrm{p}}$ does not form in an appreciable amount until most of the $\mathrm{HC}$ has been consumed. As $\beta_{g}$ increases, formation of $\mathrm{A}_{2}^{\mathrm{p}}$ occurs earlier and in the limit of $\beta_{g}>>1$ approaches instantaneous partitioning. Panel (a) of Fig. 5 shows the dependence of $\Delta M_{o}$ on $\triangle H C$ for $\beta_{g}=0.1,1$, and 10 (at $K_{2} / K_{1}=10$ ). At $\beta_{g}=0.1$, relatively little aerosol is formed until a significant amount of $A_{2}^{\mathrm{g}}$ forms, because the second-generation product is less volatile. Eventually all the aerosol ends up as $\mathrm{A}_{2}^{\mathrm{p}}$, and the ultimate yield is independent of the value of $\beta_{g}$. A vertical portion at the end of the growth curve indicates that most of the SOA is secondgeneration product formed after the parent $\mathrm{HC}$ is consumed. If $K_{2}<K_{1}$, the first-generation product is less volatile. As the reaction proceeds, $A_{1}^{\mathrm{p}}$ evaporates and reacts to form the second-generation product, which is more volatile. As in case (b), the total mass of SOA can decrease over the course of the HC oxidation (panel (b) of Fig. 5). Note that regardless of the values of $K_{1}$ and $\beta_{g}$, the final SOA yield is identical for the same $H C(0)$. This is because all the $\mathrm{HC}$ reacted must eventually be in the form of $\mathrm{A}_{2}^{\mathrm{g}}$ or $\mathrm{A}_{2}^{\mathrm{p}}$, and hence the final SOA yield is determined only by the partitioning between $\mathrm{A}_{2}^{\mathrm{g}}$ and $\mathrm{A}_{2}^{\mathrm{p}}$.

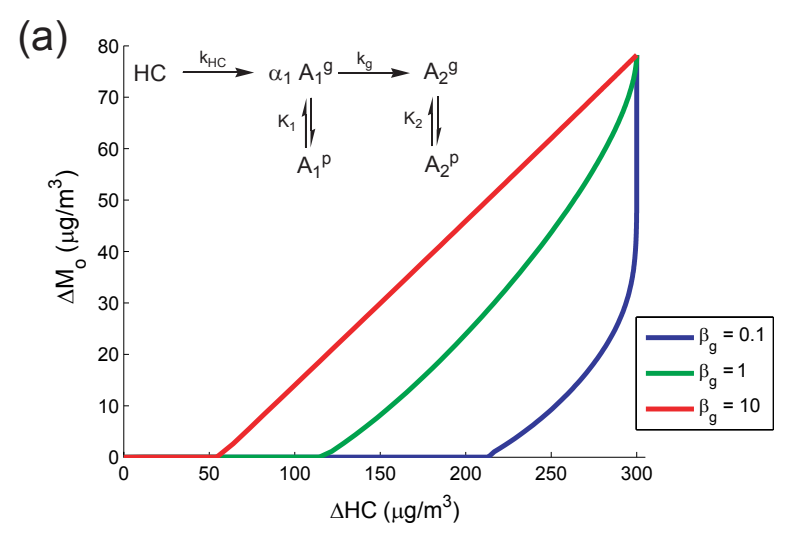

(b)

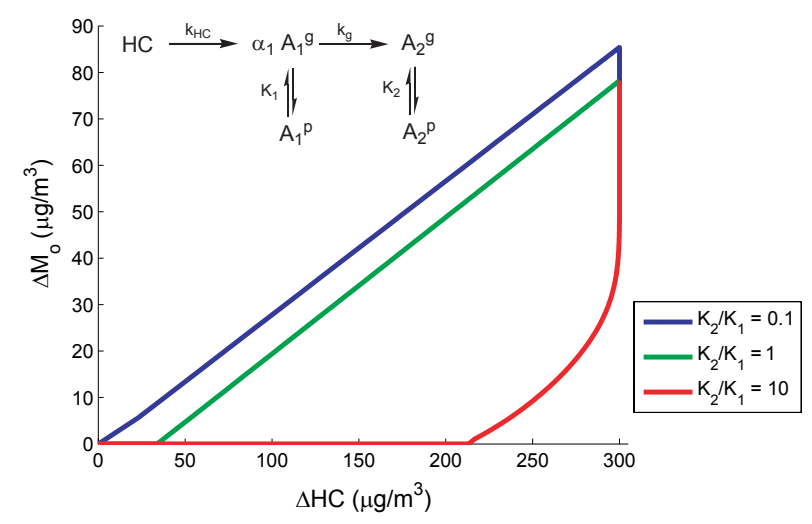

Fig. 5. Characteristic growth curves for formation of first- and second-generation semivolatile products with no aerosol-phase reaction (case (c)), with $\alpha_{1}=0.3$. Panel (a): Growth curves for slow, medium and fast further oxidation of first-generation semivolatile compound $\left(K_{1}=0.01 \mathrm{~m}^{3} / \mu \mathrm{g}, K_{2}=0.1 \mathrm{~m}^{3} / \mu \mathrm{g}\right)$. Panel (b): Growth curves of case (c) when $K_{1}>>K_{2}, K_{1}=K_{2}$, and $K_{1}<<K_{2}$ for $\beta_{g}=0.1$ and $K_{2}=0.1 \mathrm{~m}^{3} / \mu \mathrm{g}$. SOA growth for $K_{1}>>K_{2}$ (blue) decreases after all the $\mathrm{HC}$ has been reacted because the first-generation semivolatile product is further oxidized to a more volatile compound in a slow reaction step.

3.5 Case (d): Volatile first-generation product and semivolatile second-generation product

When the first-generation product $A_{1}^{g}$ is completely volatile, SOA growth results only from the second-generation product $\left(K_{1}=0\right)$, and the kinetics of this system admit an analytical solution which describes the time-dependent growth curve of the system:

$\Delta M_{o}= \begin{cases}A_{2, e q}^{p} & \text { if } A_{2, e q}^{p}>0 \\ 0 & \text { otherwise }\end{cases}$ 


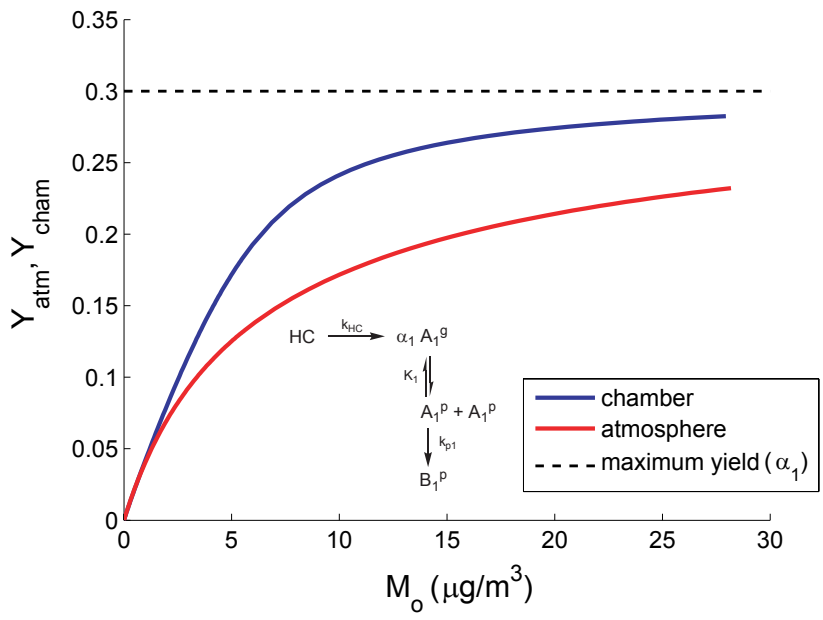

Fig. 6. Simulated SOA yields of case (e) under typical chamber experiment conditions and atmospheric conditions. The values of the parameters are $\alpha_{1}=0.3, K_{1}=0.1 \mathrm{~m}^{3} / \mu \mathrm{g}, \beta_{p 1}=1$. For the chamber simulations, no organic material is assumed to be initially present $\left(M_{O}(0)=0\right)$ and a relatively large amount of hydrocarbon is reacted $\left(H C(0)=10\right.$ to $\left.100 \mu \mathrm{g} / \mathrm{m}^{3}\right)$. The total simulation time for the "chamber" case is 1 day. For the "atmosphere" simulation, most of the aerosol loading is assumed to be from background organic material $\left(M_{o}(0)\right.$ up to $\left.28 \mu \mathrm{g} / \mathrm{m}^{3}\right)$, and a relatively small amount of parent hydrocarbon is reacted $\left(H C(0)=1 \mu \mathrm{g} / \mathrm{m}^{3}\right)$. Since the typical lifetime of SOA in the atmosphere is less than 1 week, we use 3 days as the total simulation time for the "atmosphere" case.

where

$$
\begin{aligned}
A_{2, e q}^{p}= & \frac{\left[\frac{1}{K_{2}}-A_{2}+M_{o}(0)\right]}{2} \\
& +\frac{\sqrt{\left[\frac{1}{K_{2}}-A_{2}+M_{o}(0)\right]^{2}+4 A_{2} M_{o}(0)}}{2} \\
A_{2}= & \begin{cases}\alpha_{1} \Delta H C-\frac{\alpha_{1} H C(0)}{\beta_{g}-1}\left[(1-X)-(1-X)^{\beta_{g}}\right] & \beta_{g} \neq 1 \\
\alpha_{1} \Delta H C-\alpha_{1} H C(0)(1-X) \ln (1-X) & \beta_{g}=1\end{cases} \\
X= & \frac{\Delta H C}{H C(0)}
\end{aligned}
$$

$\mathrm{A}_{2}$ represents the sum of $\mathrm{A}_{2}^{\mathrm{p}}$ and $\mathrm{A}_{2}^{\mathrm{g}}$, and $\mathrm{A}_{2 \text {,eq }}^{\mathrm{p}}$ is the concentration of $\mathrm{A}_{2}^{\mathrm{p}}$ if the gas- and particle-phases are in partitioning equilibrium. The analytical solution allows us to see more clearly the dependence of the SOA growth curve on the kinetic and equilibrium parameters: a lower $H C(0)$ requires a longer time to reach the same $\triangle H C$, which gives a higher amount of $\mathrm{A}_{2}$ (and hence, higher SOA growth) for the same $\triangle H C$. The dependence of SOA growth on the extent of reaction, $\triangle H C / H C(0)$, will be discussed in more detail.

\section{Effect of kinetic conditions on SOA growth}

\subsection{Molecularity of aerosol-phase reaction and experimen-} tal timescales

Up to this point we have assumed for convenience that the aerosol-phase reaction, e.g. $A_{1}^{\mathrm{p}} \rightarrow \mathrm{B}_{1}^{\mathrm{p}}$, is kinetically firstorder. If aerosol-phase reactions are bimolecular, such as in the formation of oligomers in the aerosol phase $\left(A_{1}^{\mathrm{p}}+\mathrm{A}_{1}^{\mathrm{p}} \rightarrow \mathrm{B}_{1}^{\mathrm{p}}\right)$, the rate of the reaction is intrinsically secondorder with respect to the aerosol-phase compound. We show in the Appendix that in this case the rate constant still has the units of inverse time. Thus the ratio of the aerosol-phase reaction rate constant to the $\mathrm{HC}$ oxidation rate constant $\left(\beta_{p 1}\right)$ is still a useful parameter for representing the relative rate of aerosol-phase reaction. Case (e) in Fig. 1 describes the case in which the first-generation semivolatile product undergoes only a second-order aerosol-phase reaction.

For the same set of parameters $\left\{k_{H C}, \beta_{p 1}, K_{1}\right\}$, in the case of second-order reaction the aerosol-phase reaction rate in case (e) decreases significantly as the concentration of $A_{1}^{p}$ approaches zero. As a result, the semivolatile compound $A_{1}$ may not be completely consumed within typical timescales of a chamber experiment, and the observed yield is lower than the theoretical yield of $\alpha_{1}$ (Fig. 6). This effect is greater when $H C(0)$ is lower because the aerosol-phase reaction rate decreases nonlinearly with respect to concentration. Unlike case (a), the SOA yield is not constant; it decreases as $M_{o}$ decreases. The system exhibits partitioning behavior similar to that seen in the Odum equilibrium model, but such behavior is not a direct result of the amount of the organic material present; rather, it occurs because of the slower aerosol-phase reaction at lower hydrocarbon concentrations.

Figure 6 also shows SOA yield curves from simulation of case (e) under typical ambient and chamber conditions. The ambient SOA yield ("atmosphere") for this case, in which the aerosol-phase reaction is bimolecular, is lower than that measured in chamber experiments ("chamber"). This occurs because the rate of the bimolecular aerosol-phase reaction is proportional to both the total concentration of semivolatile compound in the system $\left(\mu \mathrm{g} / \mathrm{m}^{3}\right.$ air) and $x_{A}$, the fraction of the condensed semivolatile compound in the organic phase ( $\mu \mathrm{g} \mathrm{A} / \mu \mathrm{g}$ organics) (see Appendix). In a typical chamber experiment, the organic aerosol generally is entirely SOA, so the fraction of the condensable species in the organic phase is high. In contrast, the absorbing aerosol in the atmosphere arises mainly from preexisting organic material, so SOA components will be substantially diluted. Hence, bimolecular aerosol-phase reactions may occur at a higher rate in chamber experiments, where relatively higher VOC concentrations are used (Kalberer et al., 2004; Paulsen et al., 2006). For the same set of parameters $\left\{k_{H C}, \beta_{p 1}, K_{1}\right\}$, the rate of a first-order unimolecular aerosol-phase reaction is faster than that of a bimolecular aerosol-phase reaction. It is therefore likely that under atmospheric conditions, the SOA yield for 


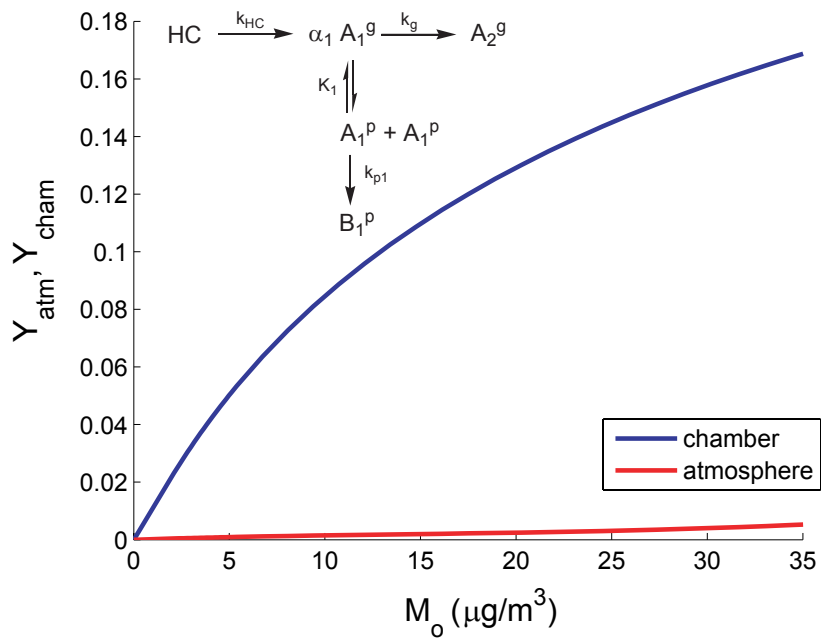

Fig. 7. SOA yields in case (f) under typical chamber experiment conditions and atmospheric conditions. For the chamber simulations, $M_{O}(0)=0, H C(0)=200$ to $700 \mu \mathrm{g} / \mathrm{m}^{3}$. For the simulations of atmosphere, $M_{o}(0)$ up to $35 \mu \mathrm{g} / \mathrm{m}^{3}, H C(0)=1 \mu \mathrm{g} / \mathrm{m}^{3}$. The values for the kinetic parameters are $\alpha_{1}=0.3, K_{1}=0.1 \mathrm{~m}^{3} / \mu \mathrm{g}$. Shown here is the SOA yield for case (f) where the gas-phase loss rate and the aerosol-phase reaction rate are comparable $\left(\beta_{g}=1, \beta_{p 1}=1\right)$. The total simulation time is 1 day for the "chamber" case, and 3 days for the "atmosphere" case.

case (a), in which the aerosol-phase reaction is unimolecular, is higher than that in case (e), where the aerosol-phase reaction is bimolecular.

Case (f) includes gas-phase loss of the first-generation semivolatile product, in addition to the bimolecular aerosolphase reaction. Since there is a competition between gasphase loss of $A_{1}^{g}$ and aerosol-phase reaction of $A_{1}^{p}$, the final SOA yield depends directly on the relative rates of these reactions. The SOA yield for such a system would be lower in the atmosphere, where the fraction of $\mathrm{A}_{1}^{\mathrm{p}}$ in the organic phase, $x_{A}$, is small and the bimolecular aerosol-phase reaction is slow (Fig. 7). Since the gas-phase loss is first-order, the SOA yield would be overestimated when applying chamber measurements to the atmosphere. On the other hand, for the same set of parameters $\left\{k_{H C}, \beta_{p 1}, \beta_{g}, K_{1}\right\}$, aerosol growth in case (b), in which the aerosol-phase reaction is unimolecular, is higher than that in case (f), where the rate of the bimolecular aerosol-phase reaction becomes much slower as $\mathrm{A}_{1}^{\mathrm{p}}$ is consumed and the fraction of $\mathrm{A}_{1}^{\mathrm{p}}$ in the organic phase $\left(x_{A}\right)$ approaches 0 .

\subsection{Rate of hydrocarbon oxidation}

$\mathrm{Ng}$ et al. (2007) and Kroll et al. (2005) reported SOA yields from the photooxidation of $m$-xylene and isoprene, respectively, that were higher than previously measured (Odum et al., 1996; Pandis et al., 1991). In these experiments, HONO is used as an $\mathrm{OH}$ precursor, which rapidly photolyzes to pro-

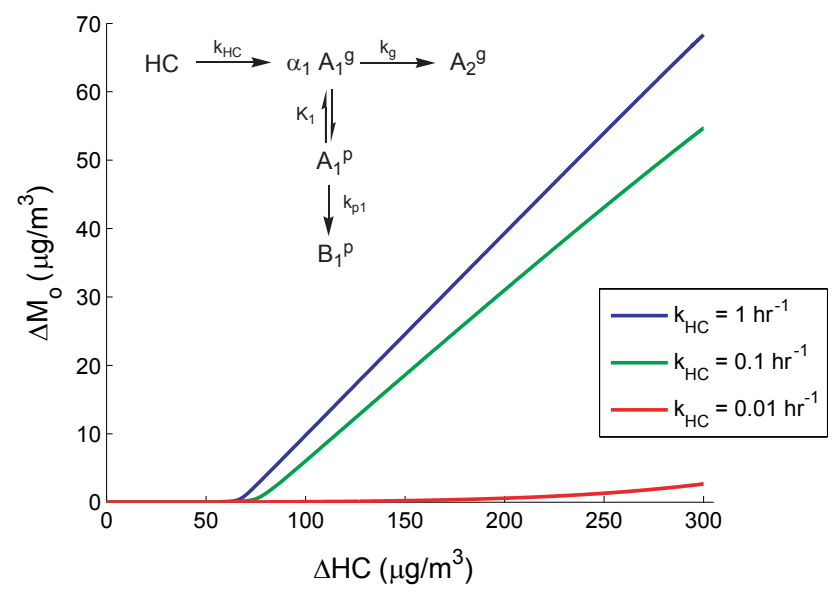

Fig. 8. Effect of $\mathrm{HC}$ oxidation rate $\left(k_{H C}\right)$ on SOA growth in case (b) with fast (blue), medium (green) and slow (red) hydrocarbon oxidation. $k_{g}=k_{p 1}=1 \mathrm{hr}^{-1}, \alpha_{1}=0.3, K_{1}=0.05 \mathrm{~m}^{3} / \mu \mathrm{g}$, $M_{o}(0)=0.01 \mu \mathrm{g} / \mathrm{m}^{3}$.

duce substantially higher concentrations of $\mathrm{OH}$ radicals than are generally formed from $\mathrm{HC} / \mathrm{NO}_{\mathrm{x}}$ irradiations. While it is possible that this increases the rate of further gas-phase oxidation to produce less volatile compounds observable within chamber timescales, here we show that the rate of hydrocarbon oxidation can cause substantial differences in SOA yield even without further gas-phase oxidation steps (in case (b)).

Figure 8 shows the growth curves for case (b) with increasing hydrocarbon oxidation rate $k_{H C}$. The rates of the other process $k_{g}$ and $k_{p 1}$ are kept constant; this assumes they are independent of $\mathrm{OH}$ concentration. At higher $k_{H C}$, the total concentration of $A_{1}$ is higher at any given time. Owing to the nonlinear nature of absorptive partitioning, the gasparticle equilibrium is shifted in favor of the particle phase when more organic material is present (Pankow et al., 1994a, b). In other words, higher total concentrations of semivolatile compound $\mathrm{A}_{1}$ leads to not only a higher absolute concentration of $A_{1}^{p}$ but also a larger ratio of $A_{1}^{p}$ to $A_{1}^{g}$ at any given time. This increases the rate of aerosol-phase reaction relative to the gas-phase loss, which increases SOA growth. Such a "rate effect" is the result of competition between gas-phase loss to nonreactive volatile compounds and aerosol-phase reaction which lowers the vapor pressure of semivolatile compounds. Therefore, there is a kinetic dependence of SOA growth on the rate of oxidation, and this highlights the need to carry out chamber experiments under atmospherically relevant rates of oxidation.

\subsection{Extent of reaction}

In the Odum model, it is assumed that the SOA yield at a particular $\triangle H C$ is independent of the extent of reaction, since SOA growth is governed only by the amount of semivolatile formed. As a result, the growth curves under different 


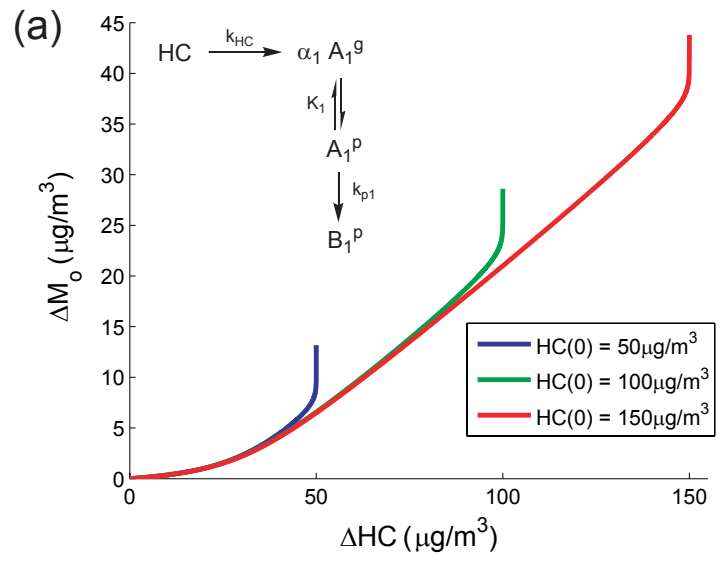

(b)

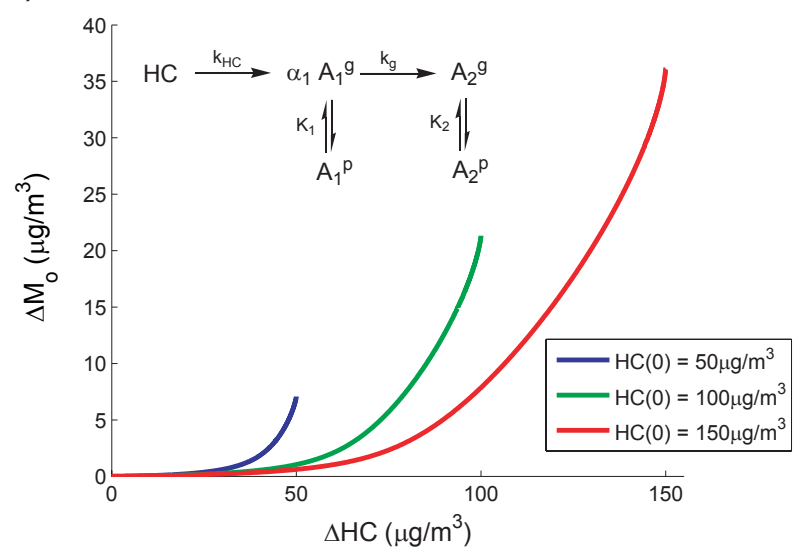

Fig. 9. Growth curves under different initial hydrocarbon concentrations, $\mathrm{HC}(0)$. Panel (a): Growth curves of case (a) with a relatively slow aerosol-phase reaction of semivolatile product $\left(\beta_{p 1}=0.1, K_{1}=0.1 \mathrm{~m}^{3} / \mu \mathrm{g}\right)$. Panel (b): Growth curves of case (c) with gas-phase reaction of semivolatile product to further generation semivolatile product $\left(K_{1}=0.01 \mathrm{~m}^{3} / \mu \mathrm{g}, K_{2}=0.1 \mathrm{~m}^{3} / \mu \mathrm{g}\right.$, $\left.\beta_{g}=0.1\right)$. In both cases, $\alpha_{1}=0.3, M_{o}(0)=1 \mu \mathrm{g} / \mathrm{m}^{3}$.

$H C(0)$ overlap. As shown in Fig. 9, when secondary reactions are present in the gas- or aerosol-phase (cases (a) and (c)), aerosol growth for different $H C(0)$ does not follow the same curve. The growth is higher for a lower $H C(0)$ at the same $\triangle H C$, because it takes longer at lower $H C(0)$ than at higher $H C(0)$ to consume the same amount of hydrocarbon, $\triangle H C$, allowing more time for the gas- or aerosol-phase reaction of the first-generation semivolatile product, producing a less volatile product. Such dependence of SOA growth on $H C(0)$ (higher growth for lower $H C(0)$ at the same $\Delta H C$ ) is also shown in Eq. (2), for the special case where the first generation product is completely volatile (case (d)). This dependence of SOA growth on initial hydrocarbon concentration has been observed in some systems ( $\mathrm{Ng}$ et al. 2006, 2007; Sato et al., 2004). As a result, when measuring SOA yield in the chamber, it is desirable to consume the parent hydrocarbon to the fullest extent for the measurement to be atmospherically relevant.
4.4 Effect of particle-phase reaction vs. further gas-phase reaction

From the overall kinetic model, one may be able to infer the relative importance of kinetic processes in a particular system by studying the behavior of the SOA growth curve exhibited by that system. In the general model in Fig. 1, both irreversible aerosol-phase reaction and further gas-phase reaction leading to products with even lower volatility are considered (ignoring the aerosol-phase reaction of $\mathrm{A}_{2}^{\mathrm{p}}$ ). Figure 10 shows the growth curves of systems in which the further gas-phase reaction that leads to an essentially nonvolatile compound is dominant $\left(\beta_{g}=1, \beta_{p 1}=0.01\right)$ and another system in which the aerosol-phase reaction is more important than further gas-phase reaction $\left(\beta_{g}=0.01, \beta_{p 1}=1\right)$. If the initial amount of organic material, $M_{o}(0)$, is small (as illustrated in panel (a) of Fig. 10), most of the semivolatile compound $A_{1}$ stays in the gas phase as $A_{1}^{g}$. In the case in which the gasphase reaction of $A_{1}$ is relatively fast, the semivolatile compound $A_{1}$ reacts to form $A_{2}$, which is essentially nonvolatile, and the delay in SOA growth is therefore short. On the other hand, if the gas-phase reaction of $A_{1}$ is relatively slow, the SOA growth is small until there is sufficient partitioning to form $A_{1}^{p}$. There is a significant delay between formation of semivolatile $A_{1}$ in the gas phase and condensation and further reaction in the aerosol phase to form the nonvolatile $B_{1}^{\mathrm{p}}$. Although the final yield is the same for these two cases (both final products $\mathrm{B}_{1}^{\mathrm{p}}$ and $\mathrm{A}_{2}^{\mathrm{p}}$ are assumed to be nonvolatile), the growth in the latter case occurs later than that in the former case. However, if there is a significant amount of background organic material (such that partitioning occurs quickly) or if the secondary reactions (gas- and aerosol-phase reactions of $\mathrm{A}_{1}$ ) are sufficiently rate-limiting compared to the oxidation of the parent hydrocarbon, the difference between the two growth curves becomes smaller and they cannot easily be distinguished from each other, as illustrated in panels (b) and (c) of Fig. 10.

\section{Application to SOA-forming systems}

\subsection{Fitting experimental data to the kinetic model}

To evaluate the extent to which it is possible to fit a unique set of kinetic and equilibrium parameters for the models in Fig. 1 to experimental data, the models were used to generate synthetic SOA growth data, which were then used as a basis for recovering the parameters used to generate the data via optimization. With the exception of case (d), in which SOA growth results only from condensation of one semivolatile compound, the "true" parameters could not be easily recovered and the minimized errors between simulated and modeled SOA growth do not necessarily represent the global minimum. In these cases, SOA growth results from either a first-generation product $\left(\mathrm{A}_{1}^{\mathrm{p}}\right)$ or a product from further gas- 
(a)

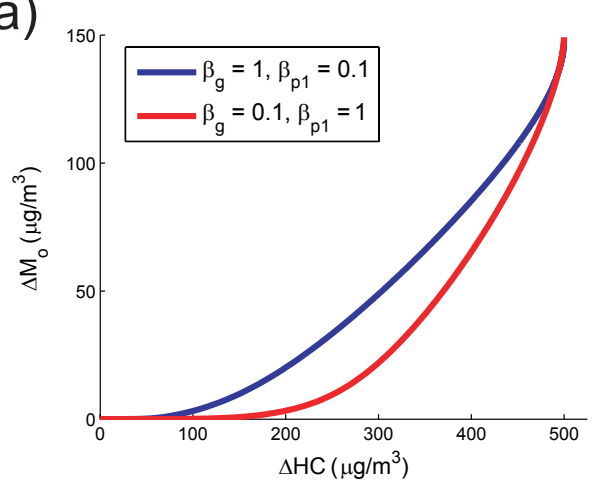

(c)

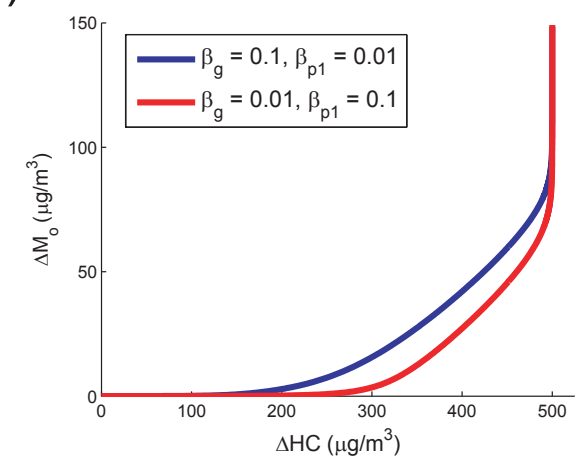

(b)
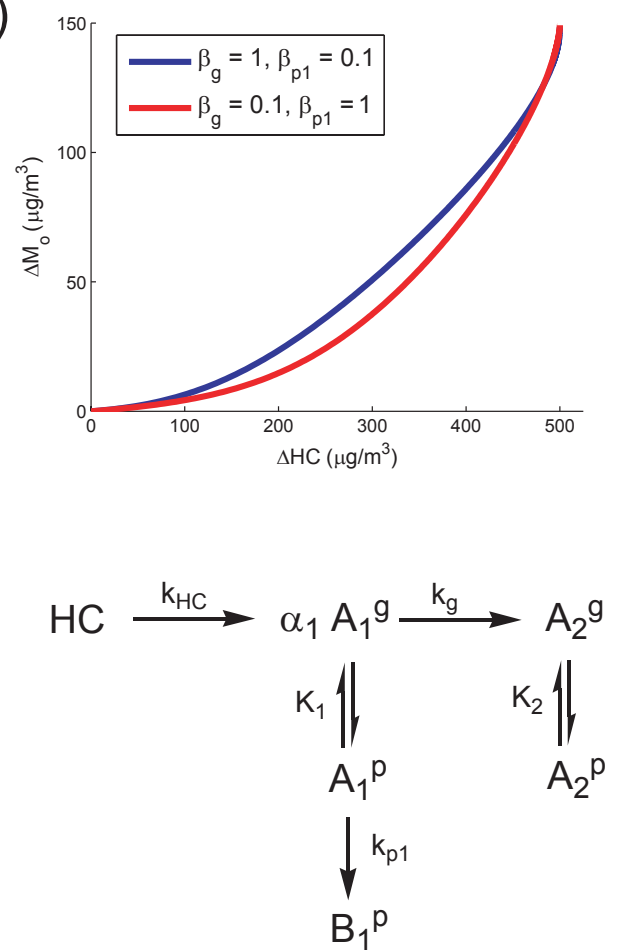

Fig. 10. Growth curves for the overall kinetic model, including both gas-phase reaction to form low volatility products and aerosolphase reaction (ignoring the aerosol-phase reaction of $\mathrm{A}_{2}^{\mathrm{p}}$ ). The blue curves represent cases in which the gas-phase reaction is faster than the aerosol-phase reaction $\left(\beta_{g}>>\beta_{p 1}\right)$, and the red curves represent cases in which the aerosol-phase reaction is faster than the gas-phase reaction $\left(\beta_{g}<<\beta_{p 1}\right)$. Panel (a): Growth curves of the overall kinetic model with a small amount of initial organic material $\left(M_{o}(0)=0.1 \mu \mathrm{g} / \mathrm{m}^{3}\right)$. Panel (b): Growth curves of the same model with a large amount of initial organic material $\left(M_{o}(0)=10 \mu \mathrm{g} / \mathrm{m}^{3}\right)$. Panel (c): Growth curves of the same model with the same amount of initial organic material as that depicted in panel (a) $\left(M_{o}(0)=0.1 \mu \mathrm{g} / \mathrm{m}^{3}\right)$, but the gas- and aerosol-phase reactions of $A_{1}$ are 10 times slower than in panel (a).

or aerosol-phase reaction $\left(\mathrm{B}_{1}^{\mathrm{p}}\right.$ or $\left.\mathrm{A}_{2}^{\mathrm{p}}\right)$. Since the measured SOA growth represents the sum of all aerosol-phase products $\left(\Delta M_{o}\right)$, some of the parameters (such as $K_{1}$ and $\beta_{p 1}$ ) are not independent and multiple sets of parameters can describe the same SOA growth curve. When the same test was performed using both measured SOA growth (total $\Delta M_{o}$ ) and the concentration of a gas-phase product (e.g. $\left.\mathrm{A}_{1}^{\mathrm{g}}\right)$, the true parameters were recovered.

Even in the case in which sufficient gas-phase data are not available in order to estimate a unique set of parameters, kinetic modeling can be used to provide a theoretical framework for interpreting trends in SOA growth data from chamber experiments and gain insight into the mechanisms of SOA formation. From the qualitative nature of timedependent growth curves, one can infer information about the kinetic mechanisms important to SOA growth and the relative rates of reaction, as shown in the following sections.

\section{$5.2 \alpha$-Pinene ozonolysis}

SOA growth data for $\alpha$-pinene ozonolysis are shown in Fig. 11 (Ng et al., 2006). The growth curves from each experiment (with varying $H C(0)$ ) can be fitted to a single growth curve of two partitioning products, which is characteristic of a system that behaves like the equilibrium Odum model. Although aerosol-phase reactions exist in the $\alpha$-pinene $/ \mathrm{O}_{3}$ system (Gao et al., 2004a; Tolocka et al., 2004; Iinuma et al., 2004), the behavior in Fig. 11 suggests that any aerosol-phase reactions are essentially reversible for this system (Kroll et al., 2005; Grieshop et al., 2007). Since the growth curves at different initial hydrocarbon concentrations overlap, the first step of hydrocarbon oxidation is rate-limiting ( $\mathrm{Ng}$ et al., 2006), such that the extent of reaction has no effect on the yield at any given $\triangle H C$. The data are consistent with an aerosol-phase equilibrium that is established quickly, and the values of the overall partitioning coefficients include the contribution from partitioning and aerosol-phase reaction equilibrium constants (Kroll et al., 2005). 


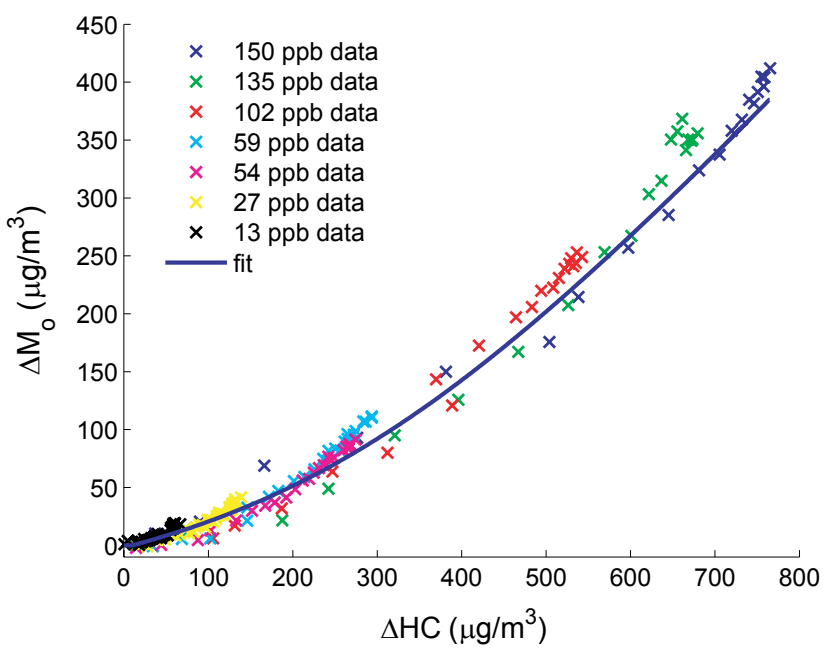

Fig. 11. Growth curves for SOA formation from $\alpha$-pinene ozonolysis at different $H C(0)$ ( $\mathrm{Ng}$ et al., 2006). Data for different experiments adhere to the prediction of the Odum model (blue line). Values for the parameters of the fitted curve are $\alpha_{1}=0.19$, $K_{1}=0.52 \mathrm{~m}^{3} / \mu \mathrm{g}, \alpha_{2}=0.64, K_{2}=0.0025 \mathrm{~m}^{3} / \mu \mathrm{g}$.

\subsection{Isoprene photooxidation under low- $\mathrm{NO}_{\mathrm{x}}$ conditions}

In studies of isoprene photooxidation under low- $\mathrm{NO}_{\mathrm{x}}$ conditions, photochemical loss of SOA mass after initial formation of SOA is observed (Kroll et al., 2006), indicative of loss of semivolatile compounds by photolysis or further oxidation reactions (Fig. 12). SOA formation likely occurs from condensation of hydroperoxides (Miyoshi et al., 1994; Kroll et al., 2006; Surratt et al., 2006), formed from reaction of $\mathrm{RO}_{2}$ with $\mathrm{HO}_{2}$ radicals, and the growth behavior exhibited in this system is likely due to a mechanism similar to case (b) of the kinetic model.

Figure 12 shows that the time-dependent SOA growth data are consistent with case (b) of the kinetic model. Fitting of the data shows that the gas-phase loss of semivolatile products is about one order of magnitude slower than formation of the semivolatile product $\left(k_{g}=k_{H C} \beta_{g} \approx 0.003 \mathrm{~min}^{-1}\right)$. The formation of products in the aerosol phase, evidenced by decrease in peroxide concentrations and increase in high-MW product concentrations over time (Kroll et al., 2006; Surratt et al., 2006), is even slower $\left(k_{p 1}=k_{H C} \beta_{p 1} \approx 0.0003 \mathrm{~min}^{-1}\right)$; the net result is that the condensed semivolatile compounds evaporate as gas-phase semivolatiles react and the total SOA mass decreases over time.

\section{$5.4 m$-Xylene photooxidation under low- $\mathrm{NO}_{\mathrm{x}}$ conditions}

Figure 13 shows SOA growth during photooxidation of $m$ xylene under low- $\mathrm{NO}_{\mathrm{x}}$ conditions ( $\mathrm{Ng}$ et al., 2007). The divergence of the growth curves at different $H C(0)$ suggests that the mechanism contains multiple reaction steps to form SOA, and the oxidation of $m$-xylene is not en-

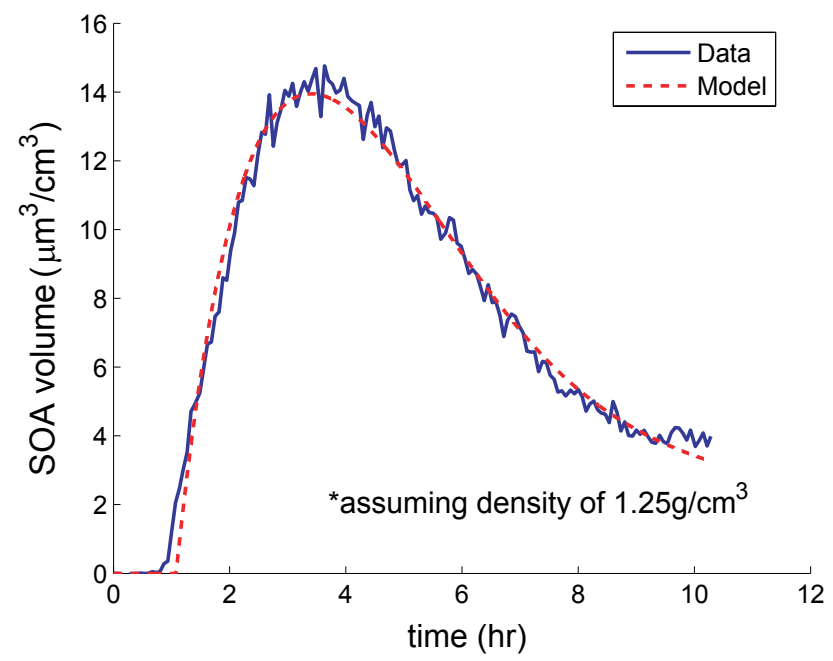

Fig. 12. SOA growth data observed during isoprene photooxidation under low- $\mathrm{NO}_{\mathrm{x}}$ conditions fit to case (b) of kinetic model. Values of the fitted parameters are $\alpha_{1}=0.30, K_{1}=0.033 \mathrm{~m}^{3} / \mu \mathrm{g}, \beta_{g}=0.24$, $\beta_{p 1}=0.027$. The rate constant of isoprene oxidation, $k_{H C}$, was measured from the hydrocarbon decay to be $0.0114 \mathrm{~min}^{-1}$. Data from Experiment 5, Fig. 2 of Kroll et al. (2006).

tirely rate-determining. Similar divergence has been observed in the photooxidation of toluene ( $\mathrm{Ng}$ et al., 2007; Sato et al., 2004). Measured SOA growth in each experiment is consistent with the general behavior of case (d), the parameters of which have been adjusted to fit the experimental growth curves, with values: $\alpha_{1}=0.383, \beta_{g}=6.45$, $K_{2}=7.01 \mathrm{~m}^{3} / \mu \mathrm{g}$. Because of the low $\mathrm{NO}_{\mathrm{x}}$ levels in these experiments, the two most likely first-generation products are organic peroxides formed from reaction of the bicyclic peroxy radical with $\mathrm{HO}_{2}$, and dimethylphenols formed from reaction of the cyclohexadienyl radical with $\mathrm{O}_{2}$ (Calvert et al., 2002). The relative magnitudes of rate constants derived from fitting of the data to case (d) $\left(\beta_{g}=6.45\right)$ are in rough agreement with literature values for photooxidation of $m$-xylene and dimethylphenols $\left(k_{\mathrm{OH}+m-x y l e n e}=\right.$ $2.31 \times 10^{-11} \mathrm{~cm}^{3} / \mathrm{molec} \cdot \mathrm{s}, k_{\mathrm{OH}+2,4-\text { dimethylphenol }}=9.1 \times$ $10^{-11} \mathrm{~cm}^{3} / \mathrm{molec} \cdot \mathrm{s}$, for a calculated $\beta_{g}$ of 3.9 ) (MCM v 3.1, http://mcm.leeds.ac.uk/MCM/), but the mass yield of dimethylphenols from $m$-xylene photooxidation as predicted by the Master Chemical Mechanism v 3.1 is only $20 \%$, suggesting that there are likely other channels that lead to SOA formation.

\section{Implications}

An idealized kinetic model is presented here that is a compact representation of different mechanisms of SOA formation, such as heterogeneous reaction, chemical loss of total SOA over time, and delayed SOA formation. The analysis reveals a number of important features of SOA formation that 


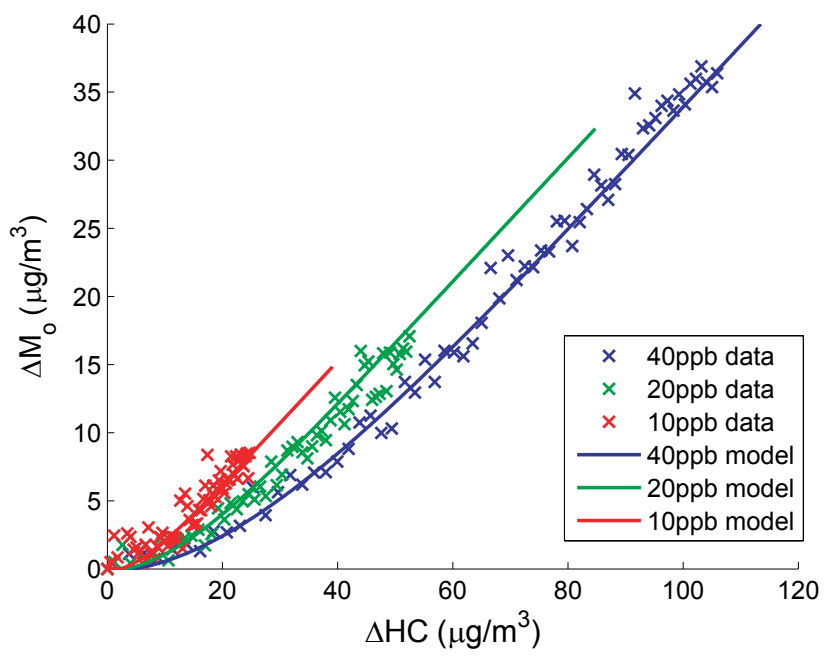

Fig. 13. SOA growth data observed during $m$-xylene photooxidation under low- $\mathrm{NO}_{\mathrm{x}}$ conditions $(\mathrm{Ng}$ et al., 2007) are consistent with case (d) of the kinetic model. The crosses represent SOA growth from each experiment, and the solid lines represent numerical solutions to case (d) of the kinetic model, with identical experimental conditions $\left(H C(0), M_{o}(0), k_{H C}\right)$. The parameters in the model are adjusted to fit the experimental data: $\alpha_{1}=0.383$, $\beta_{g}=6.45, K_{2}=7.01 \mathrm{~m}^{3} / \mu \mathrm{g}$.

are not generally appreciated. When gas-phase formation of semivolatile compounds occurs via multiple steps, the kinetics of SOA growth may differ under different initial hydrocarbon concentrations, $H C(0)$, even with the same amount of hydrocarbon reacted, $\triangle H C$. In addition, if the SOA formation mechanism involves a competition between irreversible gas-phase loss of semivolatile products to volatile compounds and irreversible aerosol-phase reaction to form additional particle-phase products, the SOA yield depends on the amount of initial organic material, even at constant total organic aerosol loading. Also, the rate of hydrocarbon oxidation can affect the SOA yield. As a result, to predict the amount of SOA formed from hydrocarbon oxidation, one must measure SOA yield under atmospherically relevant kinetic and equilibrium conditions, such as extent of reaction, seed level and rate of hydrocarbon oxidation.

Simulation of bimolecular reactions in the aerosol phase, such as oligomerization reactions, shows that these reactions can be kinetically unfavorable under atmospheric conditions, and the relative importance of these reactions could be overestimated in chamber experiments. The rate of such reactions is limited by the fraction of SOA formed from VOC oxidation in the organic phase; in ambient aerosols, this fraction is smaller than in typical chamber experiments. On the other hand, pseudo-unimolecular reactions, such as formation of organosulfates on seed aerosols containing large amounts of sulfate (Liggio et al., 2005; Liggio and Li, 2006; Surratt et al., 2007), could be relatively more important in contributing to total SOA growth. This observation again suggests that to correctly represent atmospheric SOA formation, chamber experiments should be conducted with an appropriate amount of seed such that preexisting organic material occupies a significant fraction of the final organic phase volume. Experiments exploring the effects of parameters such as seed composition and concentration on SOA yields will be useful in understanding the mechanisms of SOA growth relevant to the atmosphere.

In summary, the dominant feature of SOA formation is the gas-phase generation of semivolatile oxidation products that undergo equilibrium partitioning between the gas and particle phases. The rate at which SOA actually forms depends on the timescales of competing processes, such as multiple generations of gas-phase reactions and particle-phase reactions of semivolatile organics, which may occur over several generations; the ultimate amount of SOA that is produced can depend on the quantity of pre-existing aerosol. From the analysis presented here it is clear that, while different controlling mechanisms can lead to differing SOA growth behavior, it is not generally possible to infer the precise mechanism of SOA formation solely on the basis of the SOA growth data $\left(\triangle M_{o}\right.$ versus $\left.\triangle H C\right)$. We note that the fits to the data do not necessarily indicate the accuracy of a given mechanism. For example, it may not be possible to deduce from growth data alone the relative split between products that undergo semivolatile partitioning versus further gas-phase reaction or whether two products are formed in series or in parallel. While kinetic models presented here show how reaction rates may have a profound influence on SOA formation from a given hydrocarbon, to distinguish between reaction mechanisms that lead to similar overall SOA growth behavior requires detailed chemical measurements of gas- and aerosolphase species.

\section{Appendix A}

\section{Second-order aerosol-phase reaction involving semivolatile products}

The reaction rate per unit volume of condensed phase species $A$ that undergoes self-reaction can be expressed as:

$$
\frac{1}{V_{o}(t)} \frac{d N_{A}}{d t}=-2 k\left(\frac{N_{A}}{V_{o}(t)}\right)^{2}
$$

where $N_{A}$ is the number of moles of species $A$ in the organic phase, $V_{o}(t)$ is the volume of the organic phase, and $k$ is the second-order rate constant $\left(\mathrm{m}^{3} / \mathrm{mol} \mathrm{s}\right)$. We can express this reaction rate per unit volume of air $\mathrm{V}\left(\mathrm{m}^{3}\right)$ as:

$$
\frac{d\left(N_{A} / V\right)}{d t}=-2 k\left(\frac{N_{A}}{V}\right)^{2}\left(\frac{V}{V_{o}(t)}\right)
$$


Assuming that the mass density of the organic phase is constant, the reaction rate expressed in terms of the rate of change of the mass of $A$ in the organic phase, $m_{A}(\mu \mathrm{g})$, is:

$$
\frac{1}{M W_{A}} \frac{d\left(m_{A} / V\right)}{d t}=\frac{2 k \rho_{o}}{M W_{A}^{2} M_{o}(t)}\left(\frac{m_{A}}{V}\right)^{2}
$$

where $M W_{A}$ is the molecular weight of $A(\mu \mathrm{g} / \mathrm{mol}), \rho_{o}$ is the mass density of the organic phase $\left(\mu \mathrm{g} / \mathrm{m}^{3}\right.$ of the organic phase) and $M_{o}$ is the total mass concentration of the organic phase $\left(\mu \mathrm{g} / \mathrm{m}^{3}\right.$ of air). Upon rearranging, the reaction rate can be expressed as:

$r_{A}=\frac{d c_{A}}{d t}=-\left(\frac{2 k \rho_{o}}{M W_{A}}\right) \frac{c_{A}^{2}}{M_{o}}=-k^{\prime} \frac{c_{A}^{2}}{M_{o}}$

where $c_{A}$ is the mass concentration of $A\left(\mu \mathrm{g} / \mathrm{m}^{3}\right.$ of air). The rate constant, $k^{\prime}=\frac{2 k \rho_{o}}{M W_{A}}$, has units of $\mathrm{s}^{-1}$. Alternatively, the rate of the bimolecular aerosol-phase reaction is:

$r_{A}=-k^{\prime} c_{A}\left(\frac{c_{A}}{M_{o}}\right)=-k^{\prime} c_{A} x_{A}$

where $x_{A}$ is the mass fraction of species $A$ in the organic phase. The rate is therefore dependent on both the total concentration of $A$ in the system $\left(\mu \mathrm{g} / \mathrm{m}^{3}\right.$ of air) and the fraction of $A$ in the organic phase ( $\mu \mathrm{g} A / \mu \mathrm{g}$ organics).

Acknowledgements. This research was funded by U.S. Department of Energy Biological and Environmental Research Program DE-FG02-05ER63983.

Edited by: S. Martin

\section{References}

Bowman, F. M., Odum, J. R., Seinfeld, J. H., and Pandis, S. N.: Mathematical model for gas-particle partitioning of secondary organic aerosols, Atmos. Environ., 31, 3921-3931, 1997.

Calvert, J. G., Atkinson, R., Becker, K. H., Kamens, R. M., Seinfeld, J. H., Wallington, T. J., and Yarwoord, G.: The mechanisms of atmospheric oxidation of aromatic hydrocarbons, Oxford University Press, New York, 2002.

Czoschke, N. M., Jang, M., and Kamens, R. M.: Effect of acidic seed on biogenic secondary organic aerosol growth, Atmos. Environ., 37, 4287-4299, 2003.

Donahue, N. M., Robinson, A. L., Stanier, C. O., and Pandis, S. N.: Coupled partitioning, dilution, and chemical aging of semivolatile organics, Environ. Sci. Technol., 40, 2635-2643, 2006.

Gao, S., Ng, N. L., Keywood, M., Varutbangkul, V., Bahreini, R., Nenes, A., He, J., Yoo, K. Y., Beauchamp, J. L., Hodyss, R. P., Flagan, R. C., and Seinfeld, J. H.: Particle phase acidity and oligomer formation in secondary organic aerosol, Environ. Sci. Technol., 38, 6582-6589, 2004a.

Gao, S., Keywood, M., Ng, N. L., Surratt, J., Varutbangkul, V., Bahreini, R., Flagan, R. C., and Seinfeld, J. H.: Low-molecular weight and oligomeric components in secondary organic aerosol from the ozonolysis of cycloalkenes and $\alpha$-pinene, J. Phys. Chem. A, 108, 10 147-10 164, 2004b.
Grieshop, A. P., Donahue, N. M., and Robinson, A. L.: Is the gas-particle partitioning in alpha-pinene secondary organic aerosol reversible?, Geophys. Res. Lett., 34, L14810, doi:10.1029/2007GL029987, 2007.

Griffin, R. J., Dabdub, D., and Seinfeld, J. H.: Secondary organic aerosol - 1. Atmospheric chemical mechanism for production of molecular constituents, J. Geophys. Res., 107, 4332, doi:10.1029/2001JD000541, 2002a.

Griffin, R. J., Dabdub, D., Kleeman, M. J., Fraser, M. P., Cass, G. R., and Seinfeld, J. H.: Secondary organic aerosol - 3. Urban/regional scale model of size- and composition-resolved aerosols, J. Geophys. Res., 107, 4334, doi:10.1029/2001JD000544, 2002b.

Iinuma, Y., Böge, O., Gnauk, T., and Herrmann, H.: Aerosolchamber study of the $\alpha$-pinene $/ \mathrm{O}_{3}$ reaction: influence of particle acidity on aerosol yields and products, Atmos. Environ. 38, 761-773, 2004.

Jang, M., Czoschke, N. M., Lee, S., and Kamens, R. M.: Heterogeneous atmospheric aerosol production by acid-catalyzed particlephase reactions, Science, 298, 814-817, 2002.

Johnson, D., Utembe, S. R., Jenkin, M. E., Derwent, R. G., Hayman, G. D., Alfarra, M. R., Coe, H., and McFiggans, G.: Simulating regional scale secondary organic aerosol formation during the TORCH 2003 campaign in the southern UK, Atmos. Chem. Phys., 6, 403-418, 2006,

http://www.atmos-chem-phys.net/6/403/2006/.

Kalberer, M., Paulsen, D., Sax, M., Steinbacher, M., Dommen, J., Prevot, A. S. H., Fisseha, R., Weingartner, E., Frankevich, V., Zenobi, R., and Baltensperger, U.: Identification of polymers as major components of atmospheric organic aerosols, Science, 303, 1659-1662, 2004.

Kroll, J. H. and Seinfeld, J. H.: Representation of secondary organic aerosol (SOA) laboratory chamber data or the interpretation of mechanisms of particle growth, Environ. Sci. Technol., 39, 4159-4165, 2005.

Kroll, J. H., Ng, N. L., Murphy, S. M., Flagan, R. C., and Seinfeld, J. H.: Secondary organic aerosol formation from isoprene photooxidation under high- $\mathrm{NO}_{\mathrm{x}}$ conditions, Geophys. Res. Lett., 32, L18808, doi:10.1029/2005GL023637, 2005.

Kroll, J. H., Ng, N. L., Murphy, S. M., Flagan, R. C., and Seinfeld, J. H.: Secondary organic aerosol formation from isoprene photooxidation, Environ. Sci. Technol., 40, 1869-1877, 2006.

Kroll, J. H., Chan, A. W. H., Ng, N. L., Flagan, R. C., and Seinfeld, J. H.: Reactions of semivolatile organics and their effects on secondary organic aerosol formation, Environ. Sci. Technol., 41, 3545-3550, 2007.

Liggio, J., Li, S. M., and McLaren, R.: Heterogeneous reactions of glyoxal on particulate matter: Identification of acetals and sulfate esters, Environ. Sci. Technol., 39, 1532-1541, 2005.

Liggio, J. and Li, S. M.: Organosulfate formation during the uptake of pinonaldehyde on acidic sulfate aerosols, Geophys. Res. Lett. 33, L13808, doi:10.1029/2006GL026079, 2006.

Lim, Y. B. and Ziemann, P. J.: Products and mechanism of secondary organic aerosol formation from reactions of $n$-alkanes with $\mathrm{OH}$ radicals in the presence of $\mathrm{NO}_{\mathrm{x}}$, Environ. Sci. Technol., 39, 9229-9236, 2005.

Miyoshi, A., Hatakeyama, S., and Washida, N.: OH radicalinitiated photooxidation of isoprene - An estimate of global CO production, J. Geophys. Res., 99, 18779-18787, 1994. 
Ng, N. L., Kroll, J. H., Keywood, M. D., Bahreini, R., Varutbangkul, V., Flagan, R. C., Seinfeld, J. H., Lee, A., and Goldstein, A. H.: Contribution of first- versus second-generation products to secondary organic aerosols formed in the oxidation of biogenic hydrocarbons, Environ. Sci. Technol., 40, 2283-2297, 2006.

Ng, N. L., Kroll, J. H., Chan, A. W. H., Chhabra, P. S., Flagan, R. C., and Seinfeld, J. H.: Secondary organic aerosol formation from $m$-xylene, toluene, and benzene, Atmos. Chem. Phys., 7, 3902-3922, 2007

Odum, J. R., Hoffmann, T., Bowman, F., Collins, D., Flagan, R. C., and Seinfeld, J. H.: Gas/particle partitioning and secondary organic aerosol yields, Environ. Sci. Technol., 30, 2580-2585, 1996.

Odum, J. R., Jungkamp, T. P. W., Griffin, R. J., Flagan, R. C., and Seinfeld, J. H.: The atmospheric aerosol-forming potential of whole gasoline vapor, Science, 276, 96-99, 1997.

Pankow, J. F.: An absorption model of gas/particle partitioning of organic compounds in the atmosphere, Atmos. Environ, 28A, 185-188, 1994a.

Pankow, J. F.: An absorption model of the gas/aerosol partitioning involved in the formation of secondary organic aerosol, Atmos. Environ., 28A, 189-193, 1994b.

Paulsen, D., Weingartner, E., Alfarra, M. R., and Baltensperger, U.: Volatility measurements of photochemically and nebulizergenerated organic aerosol particles, J. Aerosol Sci., 37, 10251051, 2006.

Pun, B. K., Griffin, R. J., Seigneur, C., and Seinfeld, J. H.: Secondary organic aerosol -2 . Thermodynamic model for gas/particle partitioning of molecular constituents, J. Geophys. Res., 107, 4333, doi:10.1029/2001JD000542, 2002.
Sato, K., Klotz, B., Hateketama, S., Imamura, T., Washizu, Y., Matsumi, Y., and Washida, N.: Secondary organic aerosol formation during the photo-oxidation of toluene: dependence on initial hydrocarbon concentration, Bull. Chem. Soc. Jpn., 77, 667-671, 2004.

Seinfeld, J. H. and Pankow, J. F.: Organic atmospheric particulate material, Annu. Rev. Phys. Chem., 54, 121-140, 2003.

Seinfeld, J. H. and Pandis, S. N.: Atmospheric chemistry and physics, John Wiley, New York, 2006.

Surratt, J. D., Murphy, S. M., Kroll, J. H., Ng, N. L., Hildebrandt, L., Sorooshian, A., Szmigielski, R., Vermeylen, R., Maenhaut, W., Claeys, M., Flagan, R. C., and Seinfeld, J. H.: Chemical composition of secondary organic aerosol formed in the photooxidation of isoprene, J. Phys. Chem. A, 110, 9665-9690, 2006.

Surratt, J. D., Kroll, J. H., Kleindienst, T. E., Edney, E. O., Claeys, M., Sorooshian, A., Ng, N. L., Offenberg, J. H., Lewandowski, M., Jaoui, M., Flagan, R. C., and Seinfeld, J. H.: Evidence for organosulfates in secondary organic aerosol, Environ. Sci. Technol., 41, 517-527, 2007.

Tobias, H. J. and Ziemann, P. J.: Thermal desorption mass spectrometric analysis of organic aerosol formed from reactions of 1-tetradecene and $\mathrm{O}_{3}$ in the presence of alcohols and carboxylic acids, Environ. Sci. Technol., 34, 2105-2115, 2000.

Tolocka, M. P., Jang, M., Ginter, J. M., Cox, F. J., Kamens, R. M., and Johnston, M. V.: Formation of oligomers in secondary organic aerosol, Environ. Sci. Technol., 38, 1428-1434, 2004. 